\title{
ANALISIS PENGARUH E-COMMERCE TERHADAP PENINGKATAN KINERJA UMKM (STUDI KASUS PADA UMKM DI KABUPATEN SUMBAWA)
}

\section{The Effect of E-Commerce on MSME's Performance Improvement (Case Study on MSME's in Sumbawa District)}

\author{
Nanda Tiandra ${ }^{1}$, Denny Hambali ${ }^{2}$, Nurasia ${ }^{1}$, Nadhira Rosalina ${ }^{2}$ \\ ${ }^{1}$ Program Studi Manajemen, ${ }^{2}$ Program Studi Akuntansi, Fakultas Ekonomi dan Bisnis Universitas Teknologi Sumbawa
}

*)e-mail: nanda.tiandra@gmail.com

\begin{abstract}
The purpose of this research was to analyze the influence of E-commerce on improving the performance of MSMEs. The location of the object of research is MSMEs that produce local products on Sumbawa Regency. The analytical methode used is quantitative descriptive. To know about that performance, field observations were carried out by distributing questionnaires to find out whether E-commerce can improve the performance of MSMEs in Sumbawa district. The tests carried out were assisted with the SPSS 17.0 computer program. The results showed that E-commerce had a positive and not significant effect on the performance of MSMEs, however the existence of E-commerce is one of the marketing alternatives that used to reach more customers.
\end{abstract}

Key words: E-Commerce, Performance of MSMEs

\begin{abstract}
ABSTRAK
Tujuan dari penelitian ini adalah untuk menganalisis pengaruh E-commerce terhadap peningkatan kinerja UMKM. Lokasi yang menjadi objek penelitian adalah UMKM yang memproduksi produk lokal di Kabupaten Sumbawa. Metode analisis yang digunakan yaitu kuantitatif deskriptif. Untuk mengetahui kinerja tersebut dilakukan observasi lapangan dengan menyebar kuisioner agar dapat mengetahui apakah E-commerce dapat meningkatkan kinerja UMKM di kabupaten sumbawa. Pengujian yang dilakukan, dibantu dengan program komputer SPSS 17.0. Hasil penelitian menunjukkan bahwa E-commerce berpengaruh positif dan tidak signifikan terhadap kinerja UMKM., akan tetapi keberadaan E-commerce menjadi salah satu alternatif pemasaran yang digunakan untuk bisa menjangkau lebih banyak pelanggan.
\end{abstract}

Kata Kunci: E-commerce, Kinerja UMKM.

\section{Pendahuluan}

Usaha Mikro Kecil Menengah (UMKM) mampu bertahan dan tetap berkembang sebagai penyedia barang jasa baik ditingkat nasional maupun internasional. Menurut Ramli (2010), keunggulan UMKM di Indonesia berkembang pesat dan memberikan kontribusi besar dalam pembangunan. Hal ini dapat dilihat dari beberapa indikator, yaitu semakin bertambahnya jumlah UMKM, penyerapan tenaga kerja, sumbangan terhadap Produk Domestik Bruto (PDB). Peningkatan ini tentu saja selain dikarenakan kreativitas yang tinggi para pelaku sektor UMKM, kemampuan perusahaan dalam memilih strategi dalam memasarkan produk juga memegang peranan yang sangat penting.

Strategi pemasaran adalah suatu wujud rencana yang terurai di bidang pemasaran. Untuk hasil yang optimal, strategi pemasaran harus diterapkan semaksimal mungkin karena semakin banyaknya persaingan baik dari segi harga, pelayanan maupun kualitas produknya. Salah satu media yang dapat digunakan untuk menerapkan strategi pemasaran adalah internet. Apalagi, di Indonesia penggunaan internet semakin meningkat pesat tanpa adanya batasan usia. Menurut MarkPlus Insight, salah satu perusahaan riset terbesar di Asia
Tenggara menerangkan bahwa pengguna Internet di Indonesia memberikan gambaran jelas mengenai tren penggunaan Internet di Indonesia. Sebagaimana yang dirilis dalam Majalah Marketeers edisi Oktober 2011, menurut riset sindikasi MarkcPlus Insight, jumlah pengguna Internet di Indonesia pada tahun 2011 ini sudah mencapai 55 juta orang, meningkat dari tahun sebelumnya di angka 42 juta. Peningkatan ini mengindikasikan bahwa potensi terjadinya e-commerce di Indonesia cukup besar.

Istilah penggunaan internet sebagai media pemasaran dapat disebut e-commerce. E-Commerce menurut Ramanathan et al (2012) pemanfaatan internet sebagai media penjualan/periklanan dalam konteks B2B (Business to Business) dan B2C (Business to Consumer) serta memudahkan komunikasi dalam manajemen rantai pasokan.

Berdasarkan informasi dari Kompas tanggal 20 November 2015, e-commerce naik tajam dari Rp 96 Triliun di tahun 2013 dan nilai bisnis e-commerce di Indonesia tahun 2015 sekitar 120 Triliun sampai Rp 140 Triliun dan diperkirakan akan naik tajam senilai USD 130 Miliar di tahun 2020. Kenaikan ini 
diakibatkan seiring naiknya penetrasi pengguna telepon pintar (smartphone) yang mencapai 95,8 juta dan penetrasi internet $34,9 \%$ per tahun, diharapkan penggunaan internet ini dapat mendorong tumbuhnya e-commerce di Indonesia.

Beberapa penelitian mengatakan bahwa penggunaan $E$ commerce dapat meningkatkan kinerja perusahaan. Kumar and Petersen (2006) mengatakan bahwa dampak diterapkannya e-commerce akan meningkatkan kepuasan konsumen, berkurangnya jumlah kesalahan serta meningkatnya informasi ketersediaan sumber daya. Menurut data dari Kementerian Komunikasi dan Informatika, penjualan melalui internet oleh UMKM di Indonesia tahun 2014, 18\% pelaku UMKM sudah memiliki akses ke internet namun belum memanfaatkan untuk transaksi.

Meskipun telah didukung oleh sistem teknologi yang sangat memudahkan UMKM, masalah terbesar yang sering menghambat perkembangan UMKM di Indonesia adalah masalah permodalan atau akses kepada sumber pembiayaan. Sensus Ekonomi Nasional yang dilakukan oleh Badan Pusat Statistik tahun 2006 menunjukkan bahwa permodalan dan pemasaran menjadi permasalahan utama yang dihadapi oleh usaha mikro dan kecil (UMK). Sementara hambatan ekspansi UMK lebih didominasi oleh permasalahan permodalan atau akses terhadap sumber pembiayaan. Perasalahan ini paling banyak dirasakan oleh pengusaha yang berasal dari daerah, dimana perputaran modal tidak terlalu besar sesuai dengan UMR dan pendapatan masyarakat setempat.

Berdasarkan pada uraian di atas, peneliti akan meneliti tentang sejauh mana e-commerce memberikan peran yang terhadap perkembangan kinerja UMKM di Kabupaten Sumbawa khususnya usaha yang memproduksi atau menghasilkan

\section{Metode Penelitian}

\section{Jenis Penelitian}

Jenis penelitian yang digunakan dalam penelitian ini adalah deskriptif yaitu penelitian yang bertujuan untuk menggambarkan sifat sesuatu yang berlangsung dengan tujuan agar objek yang dikaji dapat dibahas lebih dalam. Sementara pendekatan untuk penelitian ini, peneliti memakai pendekatan kuantitatif. Pendekatan ini dapat diartikan sebagai metode penelitian yang digunakan untuk meneliti pada populasi atau sampel tertentu.

Data yang digunakan dalam penelitian ini adalah data primer, yaitu data data yang diperoleh langsung dari reaponden. Tekhnik pengumpulan data yang digunakan adalah dengan melakukan wawancara, penyebaran kuesioner, dan dokumentasi. Wawancara adalah merupakan pertukaran dua orang untuk bertukar informasi dan ide melalui tanya jawab sehingga dapat di konstruksikan makna dalam suatu topic tertentu. Penyebaran kuesioner dilakukan dengan cara mengajukan daftar pertanyaan yang secara langsung diberikan kepada responden dengan tujuan mendapatkan data yang peneliti butuhkan dalam penetian. Sementara dokumentasi adalah catatan peristiwa yang sudah berlalu (Kuncoro, 2011:240).

Untuk mengetahui pengaruh ecommerce terhadap kinerja UMKM di Kabupaten Sumbawa maka teknik analisis yang digunakan adalah regresi sederhana dengan bantuan aplikasi SPSS Statistic 17.0 Model yang digunakan dalam penelitian ini adalah:

\author{
$\mathrm{Y}=\alpha+\beta_{1} \mathrm{X} 1+\varepsilon$ \\ Keterangan: \\ Y: Kinerja UMKM \\ $\alpha:$ Konstanta \\ $\beta_{1}$ : Koefisien masing-masing variabel \\ $\mathrm{X} 1:$ E-commerce \\ $\varepsilon:$ error
}

\section{Kerangka Konseptual}

Bagan 1. Kerangka Konseptual

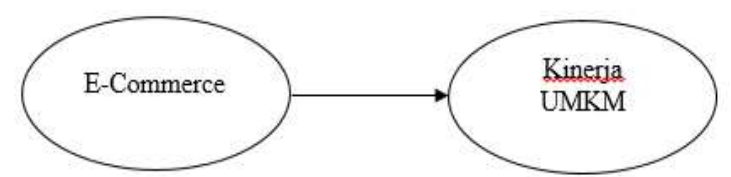

Penggunaan e-commerce adalah salah satu bentuk implementasi perkembangan teknologi untuk memasarkan produknya (barang atau jasa) ke segala tempat dan segmen, baik dalam bentuk fisik maupun digital, baik skala nasional maupun internasional. Kehadiran teknologi E-commerce membuat berbagai usaha mikro, kecil dan menengah dapat memasuki pasar global secara mudah dan bahkan bersifat realtime. Para pelaku bisnis bisa dengan mudah membangun mitra bisnis dan membangun hubungan baik dengan pelanggan. (Li \& Hong, 2013). E-commerce sebagai suatu bentuk kemajuan teknologi informasi memberikan banyak perubahan, menurunkan biaya, mempermudah promosi, peluang dalam memperluas pangsa pasar tanpa harus memiliki modal besar (Bernadi, 2013). Dengan menggunakan ECommerce dapat memperluas pangsa pasar sehingga akan berdampak pada peningkatan kinerja usaha.

Berdasarkan kerangka pemikiran yang telah di uraikan diatas, maka Hipotesis dalam penelitian ini adalah sebagai berikut :

$\mathrm{H}_{0}=$ E-Commerce tidak berpengaruh signifikan terhadap kinerja UMKM.

$\mathrm{H}_{\mathrm{a}}=\mathrm{E}$-Commerce berpengaruh signifikan terhadap kinerja UMKM.

\section{Pembahasan}

\section{Gambaran Umum Objek Penelitian}

Usaha Mikro Kecil Menengah (UMKM) merupakan tulang punggung perekonomian suatu daerah. Menurut Ramli (2010), keunggulan UMKM di Indonesia berkembang pesat dan memberikan kontribusi besar dalam pembangunan. Hal ini dapat dilihat dari beberapa indikator, yaitu semakin bertambahnya jumlah UMKM, penyerapan tenaga kerja, sumbangan terhadap Produk Domestik Bruto (PDB). Peningkatan ini tentu saja selain dikarenakan kreativitas yang tinggi para pelaku sektor UMKM, kemampuan perusahaan dalam memilih strategi dalam memasarkan produk juga memegang peranan yang sangat penting.

Di kabupaten Sumbawa terdapat banyak UMKM yang menjual produk khas daerah. Diperlukan strategi pemasaran yang tepat agar produk khas sumbawa banyak di kenal di kalangan yang lebih luas. Dengan demikian pendapatan masyarakat khususnya pelaku UMKM semakin meningkat dan dapat menopang perekonomian daerahnya.

Dengan Strategi pemasaran yang tepat, maka laba yang akan didapatkan akan semakin mudah. Untuk hasil yang optimal, 
strategi pemasaran harus diterapkan semaksimal mungkin karena semakin banyaknya persaingan baik dari segi harga, pelayanan maupun kualitas produk yang ditawarkan UMKM itu sendiri. Salah satu media yang dapat digunakan untuk menerapkan strategi pemasaran adalah internet atau $e$ commerce. Saat ini, di Indonesia penggunaan internet semakin meningkat pesat tanpa adanya batasan usia. Peningkatan ini mengindikasikan bahwa potensi terjadinya e-commerce di Indonesia cukup besar.

Menurut data dari Kementerian Komunikasi dan Informatika, penjualan melalui internet oleh UMKM di Indonesia tahun 2014, 18\% pelaku UMKM sudah memiliki akses ke internet namun belum memanfaatkan untuk transaksi. Oleh karena itu diperlukan kesadaran pelaku UMKM agar dapat memanfaatkan fasilistas teknologi yang tersedia dan bebas di akses oleh siapapun tanpa batas untuk meningkatkan pendapatannya.

Karakteristik responden menurut lama penggunaan $E$ commerce:

Diagram 1: Responden Menurut Lama Penggunaan E-Commerce

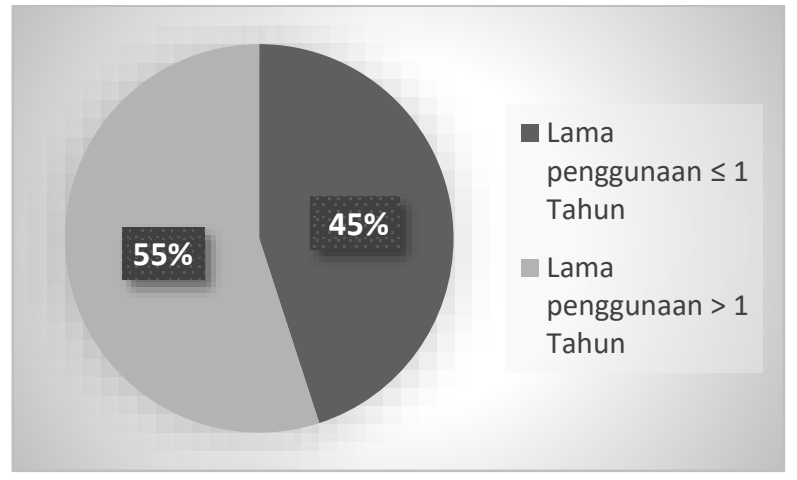

Sumber: Data diolah

Dari diagram di atas menunjukkan bahwa lama penggunaan $E$ commerce di atas satu tahun ada $55 \%$ dan dibawah satu tahun adalah $45 \%$. Artinya masih banyak dari mereka (responden) yang baru menggunakan E-commerce dalam keguatan usaha mereka.

Sementara itu karakteristik reponden menurut produk yang dimiliki adalah:

Diagram 1: Responden Menurut Jenis Produk yang di Jual ECommerce

- Permen Susu $\quad$ - Susu Kuda Liar - Kre Alang
- Madu
- Parang

Sumber: Data diolah
Dari diagram 2 diatas dapat dilihat bahwa penggunaan $E$ commerce didominasi oleh UMKM Madu, Permen Susu, Kre Alang. Sedangkan untuk UMKM Parang dan Susu Kuda Liar masih sangat rendah.

\section{Hasil Analisis E-Commerce Terhadap Kinerja UMKM di Kabupaten Sumbawa}

Uji regresi digunakan untuk mengetahui pengaruh $E$ commerce terhadap kinerja UMKM. Berikut hasil estimasi uji regresi sederhana:

Tabel 5.4 Hasil Estimasi Uji Regresi

\begin{tabular}{|c|c|c|c|}
\hline \multicolumn{2}{|c|}{ Model } & B & Sig. \\
\hline \multirow{2}{*}{1} & (Constant) & 12.277 & .033 \\
\cline { 2 - 4 } & E-commerce & .275 & .119 \\
\hline
\end{tabular}

Sumber: Data Diolah

Estimasi model yang didapatkan dari hasil uji regresi yang ditunjukkan pada Tabel 5.4 adalah sebagai berikut:

$$
\mathrm{Y}=12.277+0.275 \mathrm{X} 1+\varepsilon
$$

Dari hasil estimasi model di atas yang ditunjukkan pada Tabel 5.4 bahwa variabel E-commerce jika dilihat dari tingkat signifikansi yang dimiliki lebih besar dari 0.05 yaitu sebesar 0.119 , yang berarti bahwa E-commerce tidak mempunyai pengaruh yang signifikan terhadap kinerja UMKM. Hal ini juga didukung oleh penelitian yang dilakukan oleh Nurhadi (2015) yang menyatakan bahwa E-commerce tidak berpengaruh signifikan terhadap kinerja organisasi. Temuan lainnya yang dilakukan oleh Wangari (2013) yang menyatakan bahwa E-commerce tidak berpengaruh signifikan terhadap kinerja keuangan. Ini disebabkan karena belum optimalnya penggunaan E-commerce dalam kegiatan usaha. Meskipun UMKM mempunyai kesempatan yang sama untuk menggunakan E-commerce sebagai salah satu alternatif untuk memaksimalkan kinerja. Akan tetapi tidak semua UMKM mempunyai kapabilitas dalam menggunakan dan memanfaatkan E-commerce secara maksimal. Pengetahuan dan keahlian pengguna dapat menjadi salah satu penyebab perbedaan kemampuan dalam mengoperasikan E-commerce. Sehingga hal tersebut tidak terlalu berpengaruh terhadap kinerja UMKM.

Namun demikian nilai koefisien yang dihasilkan yaitu sebesar 0.275 yang ditunjukkan pada Tabel 5.4 diatas. Hal tersebut mengindikasikan bahwa E-commerce berpengaruh positif terhadap kinerja UMKM, dimana semakin tinggi derajat penggunaan atau pemanfaatan E-commerce maka akan menaikkan kinerja UMKM secara rata-rata.

Secara umum hadirnya E-commerce menjadi salah satu solusi efektif bagi para pengusaha khususnya UMKM untuk menembus pasar global yang akan meningkatkan daya usaha, sehingga akan berdampak pada kinerja operasional maupun finansial (Khan \& Motiwalla, 2002:507). Manfaat lain yang diberikan oleh $E$-commerce adalah membantu dalam membuat basis data client, mempercepat akses informasi, penghematan biaya, dan meningkatkan mutu layanan pelanggan (Huy, et al., 2012).

Banyak keuntungan dan manfaat yang dapat dinikmati dengan adanya E-commerce. Bagi UMKM penerapan E-commerce 
dapat meningkatkan mutu pelayanan pelanggan. Pelanggan tidak lagi harus mendatangi outlet usaha dan mengantri hanya untuk mendapatkan produk yang diinginkan. Mereka bisa membuat transaksi dimana dan kapanpun mereka inginkan. Dukungan terhadap penyediaan akses informasi yang lebih rinci untuk pelanggan atau calon pelanggan juga disediakan oleh E-commerce. Mereka dapat dengan mudah memperoleh informasi baik itu tentang harga maupun detail produk melalui salah satu E-commerce yang digunakan oleh pealaku UMKM. UMKM juga dapat menekan biaya promosi melalui aplikasi periklanan atau market place untuk menyajikan berbagai program promosi penjualan dengan jangkauan konsumen potensial yang luas secara efisien. UMKM dapat melakukan promosi selama selama 24 jam tanpa henti. Model transaksi ini memungkinkan transaksi melewati batas-batas wilayah dengan jauh lebih mudah dengan biaya yang efektif daripada perdagangan yang bersifat tradisional. sehingga E-commerce hadir menjadi salah satu strategi pemasaran yang efektif untuk memasarkan produk lokal.

Penggunaan teknologi E-Commerce secara intensif menurut Burdonaba et al. (2012) dapat meningkatkan daya saing serta meningkatkan efisiensi rantai nilai bagi perusahaan (dalam Nurhadi, 2015). E-commerce menawarkan berbagai macam peluang bagi UMKM tanpa harus mengeluarkan biaya lebih untuk meningkatkan efisiensi kerja baik efisiensi tenaga kerja ataupun efisiensi waktu.

\section{Kesimpulan}

Berdasarkan landasan teori dan di dukung oleh analisis data hasil uji instrumen penelitian, maka dapat di simpulkan sebagai berikut:

a. Penggunaan E-commerce tidak berpangaruh signifikan terhadap kinerja UMKM. Dilihat dari estimasi model yang menunjukkan bahwa tingkat signifikansi adalah sebesar 0.119 berada di atas 0.05. Meskipun UMKM mempunyai kesempatan yang sama untuk menggunakan E-commerce sebagai salah satu alternatif untuk memaksimalkan kinerja. Akan tetapi tidak semua UMKM mempunyai kapabilitas dalam menggunakan dan memanfaatkan E-commerce secara maksimal. Pengetahuan dan keahlian pengguna dapat menjadi salah satu penyebab perbedaan kemampuan dalam mengoperasikan E-commerce. Sehingga hal tersebut tidak terlalu berpengaruh terhadap kinerja UMKM.

b. Walaupun E-commerce tidak mempunyai pengaruh yang signifikan terhadap kinerja UMKM, akan tetapi kehadiran E-commerce menjadi salah satu alternative pemasaran yang digunakan untuk bisa menjangkau lebih banyak pelanggan. UMKM dapat melakukan promosi dimana saja dan kapan saja selama selama 24 jam tanpa henti. Model transaksi ini memungkinkan transaksi melewati batas-batas wilayah dengan jauh lebih mudah dengan biaya yang efektif daripada perdagangan yang bersifat tradisional.

\section{Saran}

Berdasarkan hasil observasi mengenai peran e-commerce terhadap kinerja UMKM maka saran yang dapat diberikan antara antara lain:

a. Bagi UMKM diharapkan dari hasil akhir penelitian ini nantinya akan dapat di gunakan sebagai acuan untuk mengambil keputusan dalam mengembangkan kinerja UMKM yang ada di kabupaten Sumbawa. Karena dilihat dari potensi yang dimiliki sangat berpeluang mendapatkan laba yang meningkat dengan memanfaatkan sarana pemasaran e-commerece.

b. Serta bagi peneliti selanjutnya agar mengembangkan dan memperluas konten, serta objek dan scope penelitian agar dapat memberikan manfaat yang lebih besar lagi dibandingkan dengan yang telah dilakukan dalam penelitian ini.

c. Bagi Pemerintah, pemerintah perlu terlibat aktif mendukung penggunaan sistem E-Commerce terutama dalam sistem pemasaran produk-produk UMKM. Peran lainnya dari pemerintak adalah diharapkan pemerintah mengadakan pembekalan keterampilan kepada pelaku UMKM, sehingga mereka dapat memanfaatkan kesempatan dan teknologi yang ada.

\section{Daftar Pustaka}

Badan Pusat Statistik.2015.Sumbawa Dalam Angka 2015. http://www.sumbawakab.bps.go.id (akses tanggal 26 Mei 2016)

Bernadi, J. 2013. Aplikasi Sistem Informasi Penjualan Berbasis Web Pada Toko Velg YQ.ComTech. 4(2). Hlm. 731-741.

Huy, L.V., Rowe, F., Truex D. and Huynh, M.Q., 2012, An empirical Study of Determinants of E-Commerce Adoption in SMEs in Vietnam an economy in transition, Journal of Global Information Management, Vol. 20 No. 3, pp. 23-54

Juliandi, Azzuar. 2007. Teknik Pengujian Validitas dan Reliabilitas. http:/www.azuarjuliandi.com/elearning/

Kemendikbud. 2015.2 Parang. http://www.cagarbudaya.kemdikbud.go.id (akses tanggal 19 April 2016)

Kotler, P. Gary, A. 2008. Prinsip-prinsip Pemasaran. Jakarta: Erlangga.

Li, H., \& Hong, J. 2013. Factors Influencing Consumers' Online Repurchasing Behavior: A Review and Research Agenda. iBusiness. 5(4). Hlm.161-166.

Ningrum, Putri Ardhanareswari Hamardika. 2010. Analisis Strategi Pemasaran Usaha Jasa Pembuatan dan Perbaikan Furniture UD. Suryani Furniture, Bogor, Jawa Barat. Skripsi. Fakultas Ekonomi dan Manajemen Institut Pertanian Bogor, Bogor.

Nurhadi. 2015. Anteseden Penggunaan E-Commerce: Pengaruhnya Terhadap Manajemen Pengetahuan Dan Kinerja Organisasi (Studi Pada Hotel Berbintang Di Provinsi Bali). Disertasi. Malang: Universitas Brawijaya

Rahmat, Reny Maulidia. 2012. Analisis Strategi Pemasaran pada PT. Koko Jaya Prima Makassar. Skripsi. Fakultas Ekonomi dan Bisnis Universitas Hasanuddin, Makassar.

Ramli, N. 2010. Keberadaan UMKM. Republika Online. 2010. 
Sugiyono. 2013. Metode Penelitian Kuantitatif Kualitatif dan $R \& D$. Bandung: Alfabeta

Tjiptono, F. 2008. Strategi Pemasaran. Andi. Yogyakarta.

Umar, H. 2008. Manajemen Strategi in Action. PT. Gramedia Pustaka Utama. Jakarta
Wangari, Wanguku Irene. 2013. The Effect of Electronic Commerce on The Financial Performance of Airlines Kenya: A Case Study of Kenya Airways. University of Nairobi. 